\title{
Accurate measurement methods show high atmospheric oxidized mercury in the western United States
}

\author{
SETH LYMAN ${ }^{1}$, TYLER ELGIAR ${ }^{1}$, LYNNE GRATZ $^{2}$, MAE \\ GUSTIN $^{3}$ AND SARRAH DUNHAM-CHEATHAM ${ }^{3}$ \\ ${ }^{1}$ Utah State University \\ ${ }^{2}$ Colorado College \\ ${ }^{3}$ University of Nevada, Reno \\ Presenting Author: seth.lyman@usu.edu
}

Most mercury pollution is emitted into the atmosphere, and the atmosphere serves to transport and chemically transform mercury before it deposits to ecosystems. Several recent theoretical studies have greatly advanced our understanding of probable atmospheric oxidation-reduction processes. Unfortunately, commercial measurement techniques for atmospheric oxidized mercury are fraught with uncertainty and bias, making it impossible to use them to verify these theoretical claims.

We have developed a permeation tube-based oxidized mercury calibration system and a cation-exchange membrane-based dualchannel measurement device to overcome these challenges. Field calibrations show that, unlike $\mathrm{KCl}$ denuder-based measurement systems, the dual-channel system is able to quantitatively capture oxidized mercury compounds $\left(\mathrm{HgBr}_{2}\right.$ and $\left.\mathrm{HgCl}_{2}\right)$ that are injected by the calibrator. We have deployed the dual channel system and calibrator at several locations around the western United States.

Behavior of surface-level oxidized mercury as measured with the dual-channel system were similar to those measured in the western U.S. using $\mathrm{KCl}$ denuder-based measurements, including higher concentrations in the daytime and during summertime periods with evidence of transport from the Pacific anticyclone. Dual-channel-derived concentrations were much higher than those from $\mathrm{KCl}$ denuder-based measurements, however, exceeding $10 \%$ of total atmospheric mercury on many occasions. Further, extreme wildfire events in California during summer 2020 led to very high oxidized mercury and elevated elemental mercury in the Reno, Nevada area. Also, we did not observe oxidation of elemental mercury during periods with active ozone photochemistry (ozone $>100 \mathrm{ppb}$ ) under cold-pool conditions in Utah, which thermally isolated the surface from the free troposphere.

These measurements, and other cation-exchange membranebased measurements occurring around the world, are allowing us to quantitatively understand oxidized mercury behavior and transport for the first time. 